\title{
O JARDIM JAPONÊS NA ESTÉTICA DA NATUREZA CONTEMPORÂNEA
}

Tiago Mesquita Carvalho

(Mestrando em Filosofia, FLUL)

A categoria estética do jardim possui um carácter peculiar. Não é apenas artefacto artístico ponderado que ganha materialidade ao ser subtraído ao pensamento, nem lugar selecto retirado de uma natureza pura. Apesar de se poderem conceber vários graus de planeamento, selectividade e até estro por parte do seu criador, há uma diferença fundamental que distingue a arte do jardim das demais. A sua matéria é viva, é pulsante. Ela não está remetida em definitivo a uma dada forma, estática; o jardineiro não é tanto o responsável quanto o colaborador das possíveis formas que a natureza the permite concretizar. De certo modo, pode-se afirmar que o jardim reside na fronteira entre a arte e a natureza e, portanto, entre os desígnios mais altos do espírito humano enquanto expressão e o mundo envolvente no qual ele se acha mergulhado. O pendor de um dado jardim para revestir-se de uma matiz ora mais natural, ora mais artificial, revela a sensibilidade na qual ele se arvora; nas relações entre os seus elementos constituintes e o sujeito resume-se, recôndita, toda uma estética; na maneira em que assoma aos sentidos e recoloca o homem no seu interior, toda uma ontologia. $\mathrm{O}$ jardim não esconde. No seu seio voga então, invisível mas palpável, uma lei quanto à relação do humano com a natureza e que importa clarificar.

Ao Japão associam-se comummente duas religiões que ressumaram os seus conteúdos na arte e cultura das gentes do arquipélago e que por isso se reflectiram no jardim. Ao Xintoísmo, religião endógena, panteísta e imanente, reserva-se uma breve referência. A posição da natureza nessa cosmogonia está prenhe de uma carga espiritual sagrada que permeia os vários elementos físicos da paisagem japonesa: as montanhas, os rios, os vales, as rochas, os ventos, o oceano; todos eles eram prática de adoração por se crerem possuídos de divindade. O seu predomínio foi minguando,

Philosophica, 32, Lisboa, 2008, pp. 77-91 
em especial aquando da introdução do Budismo provindo da China, mas em nenhum momento tornou-se desprezível. Dir-se-ia antes que ambas se moldaram e adaptaram mutuamente, de modo a que a situação religiosa actual contém traços quer de uma quer de outra. Essa fusão conservou porém as diferenças de ambas, embora reconfigurando-lhes conexões que permitem estabelecer linhas de continuidade; considera-se que o contexto religioso no Japão era já propício à sua introdução e que a imanência colocada nos elementos naturais, ao não ser negada pelas novas ideias, contribuía para a sua aceitação e acusava já os primevos traços da sensibilidade japonesa. A análise deste trabalho quer-se cingir então apenas àqueles jardins influenciados pela tradição Zen do Budismo, porque filosoficamente mais rico e de sabor mais claro e distinto.

Se quisermos apreciar ou pelo menos degustar a subtileza que preside às artes influenciadas pelo Zen deve-se traçar e caracterizar as suas origens. Proveniente da Índia, o Budismo chegou à China na forma proclamada por Nagarjuna. A doutrina deste filósofo era uma refutação intelectual de todos os principais sistemas filosóficos do seu tempo apoiada por uma crítica epistemológica robusta e semelhante à de David Hume. Afirmando o Budismo a transitoriedade de todas as coisas, a posição de Nagarjuna é interpretada como uma refinação dessa sentença. Em comum permanece a ideia de que se o universo é de facto caracterizado por uma extrema multiplicidade de formas em constante devir, todo o sofrimento humano provém do desejo e apego a elementos fátuos que aparentam solidez e imutabilidade. As questões acerca da origem e destino do Universo são preteridas em favor do facto mais evidente que é o sofrimento humano e da possibilidade da sua salvação num mundo desprovido de esteios. Nagarjuna estende essa acepção céptica às próprias ideias de realidade e estabelece que o carácter lábil do que é não pode ser confundido ou identificado com nenhuma ideia. Todas as nossas ideias são também desprovidas de natureza própria, não se originam nem por si mesmas nem a partir de si mesmas mas estão contudo interligadas e encadeadas de um modo aparentemente tão natural que torna-se bastante sedutor e até lógico considerá-las como a própria expressão ou explicação daquilo que há. Porque a mente é discriminativa, a sua actividade consiste em classificar e atribuir características de semelhança, regularidade, diferença e progressivamente constituir classes e géneros até substancializar tudo o que lhe é exterior. A filosofia de Nagarjuna consiste em sublinhar o carácter convencional destas construções da razão, desmontando-as quanto à sua perenidade, validade e autonomia; essas divisões e limites são mais características da linguagem e do pensamento do que propriedades do mundo, ou seja, o que se afirma é um radical relativismo em que a lógica e o significado são mais características duma certa espécie de operacionalidade mental do que uma imagem fidedigna do real. Portanto, quanto à possibilidade de conhecimento dos princípios ontológicos da rea- 
lidade, é-nos negada a possibilidade de os podermos sequer indicar, pelo menos de maneira abstracta; e no entanto, as coisas estão aí, e no meio do aparente vazio teórico, assoma um mundo concreto de experiência, imerso num domínio não verbal e anterior a qualquer conceitualização. Um Buda é portanto aquele que despertou para um mundo primário e vazio porque anterior a qualquer descrição, não o confundindo com qualquer ideia de realidade; ele encara-o sem qualquer linhas de divisão e portanto evita, não se esforçando, imprimir-lhe qualquer separação entre acontecimentos de categorias opostas; nem o bom ou o mau, nem o ser ou o não ser, nem o permanente ou o transitório, nem o passado ou o futuro. Ele permite-se à total disponibilidade do real. $\mathrm{O}$ ímpeto para conferir à realidade a arquitectura da mente é, no Budismo, encarado como extremamente natural mas não é de todo o seu substrato mais profundo; tampouco ele se resguarda nalguma posição contrária às capacidades reflexivas da mente humana, dada a sua inegável utilidade. Passa-se apenas que tal estrutura não se pode auto-sustentar nem justificar através de si mesma. $\mathrm{O}$ despertar é nítido e claro porque aflora na aceitação plena dos fenómenos do mundo, na sua gratuita tal-idade; então, a natureza é encarada como uma teia extremamente harmoniosa, auto-organizada a partir de si própria; todos os acontecimentos surgem então por si e sem propósito, inclassificáveis, espontâneos.

Aquando da penetração do Budismo na China, este deparou-se com duas escolas filosóficas já existentes. O Confucionismo é tradicionalmente associado às convenções linguísticas, éticas, legais e rituais que fornecem à sociedade o seu sistema de comunicação. É uma filosofia ética extremamente pragmática que possui a vantagem de ser funcional enquanto não deriva as suas teses morais de uma ordem divina; como qualquer ordem lógica e social necessária ao funcionamento social e respectiva hierarquização, ela terá de joeirar algumas características humanas em detrimento de outras. São essas qualidades humanas vergadas à latência que o Taoísmo se propõe a despertar. Tal como no Budismo, na génese desta filosofia reside a vontade de restituir o homem à sua natureza original e até desenvolver as faculdades menosprezadas por uma adaptação às rígidas convenções. Esta fuga à ordem social é então uma tentativa de subtrair o indivíduo à ordem do conhecimento normativo e legal no qual ele estava inserido; é a reinserção na natureza que afinal sempre foi a sua e que é idêntica à de todo o Universo; é o regresso a um saber corpóreo e imediato, não regulado e à qualidade mais apreciada pelos chineses: a espontaneidade original (tzu-jan). Como movimento de cariz mais individualista, a própria existência de uma escola que se propunha a retirar os indivíduos duma sociedade altamente hierarquizada, onde a harmonia do colectivo era amiúde favorecida, é digna de nota. A sua compatibilidade com o Confucionismo é explicada pelas bases ontológicas em que ambos 
se arrimam, daí que seja fácil compreender a sua complementaridade. Sobretudo, e em contraste com a experiência Ocidental, uma crítica à ordem social e lógica da necessidades das convenções não implicava uma iconoclastia contra o divino ou o absoluto, sublinhando-se novamente o acordo tácito e pragmático em que se baseava o Confucionismo. Esse acordo não brotava de algo sacralizado e desta forma, negá-lo não ocorria numa revolta contra o próprio fundamento ontológico. Este não é nem conceito abstracto entronizado pela razão humana nem Deus omnipotente e criador e, sobretudo, a sua qualidade não é a omnisciência; ele não é objecto do seu próprio conhecimento; ora, o Tao é somente o princípio que na filosofia chinesa jaz inerente ao mundo e que age segundo a espontaneidade. O seu domínio é o do concreto e ao se lhe atribuir uma palavra pretende-se tão só designar algo que é em si indefinível mas que permeia toda a realidade; ele é o ritmo da eterna mutação que funciona por si mesmo, acontecendo. A importância é atribuída ao processo, não ao resultado. Daí que à pergunta de se saber quem criou a Natureza não possa haver, nesta mentalidade, uma resposta, pois esta cresce e desenvolve-se sem pretender seguir um qualquer plano. Usando uma analogia, claro que torna-se-nos extremamente complicado exaurir a explicação do funcionamento dos nossos corpos em termos de uma linguagem científica e abstracta e, no entanto, é indubitável que sabemos como usá-lo apesar de permanecermos ignorantes quanto ao modo como o fazemos. Daí que o homem do Taoísmo seja aquele que radique nas virtudes desafectadas e sem propósito que tanto de comum têm afinal com a sua visão da realidade; ele usa a sua inteligência, inata e espontânea, sem esforço. Essa capacidade é reconhecida como $T e$ e, bem ao estilo paradoxal de comunicação dos seus mestres, ela é realmente virtude superior porque não se sabe como virtude, enquanto a virtude que se guia pela virtuosidade é virtude inferior ${ }^{1}$. Novamente, há uma apologia do concreto e do inevitável real, eximindo-se os conceitos abstractos da tarefa do seguidor do Tao de remontar a sua concentração para esse presente tangível. Segundo o Tao Te King:

O sem nome é a origem do céu e da terra;

Nomear é a mãe das dez mil coisas ${ }^{2}$

O que se pretende não é atribuir ao mundo a propriedade de uniforme ou múltiplo, pois essa afirmação supõe já uma demarcação e, por isso, distingue entre si as várias coisas. Só quando já não há cunhagem ou classificação alguma é que o mundo aparece vago e vazio e só aí é que

1 Alan Watts, O Budismo Zen, Lisboa, Editorial Presença, 2000, pp. 41-44.

2 Lao Tzu, Tao Te King. O caminho da virtude, Lisboa, Europa-América, 1997, p. 5. 
$T e$, virtude espontânea e livre, pode surgir e manifestar-se sem qualquer tipo de obstáculo. E contudo o Tao exige ser cultivado; não pode ser alcançado nem por palavras nem pelo silêncio.

O Zen surge assim na China como uma adaptação natural do Budismo ao pensamento chinês, já que, segundo o que foi exposto, são tão notórias as suas semelhanças que a possibilidade de um contacto prévio não é uma hipótese negligenciável. Após o seu franco declínio em território chinês, o Zen estava já estabelecido no Japão onde continuaria a florescer e a influenciar de modo indelével todos os aspectos duma cultura. Constitui a sua característica mais particular um certo modo directo de se exercer e de transmitir essa própria natureza original, espontânea, apontando a própria coisa e não se atendendo às representações. Embora a sua faceta mais comum e aquela que justifica a formação de comunidades monásticas seja a meditação, todo o seu espírito está presente em várias actividades; sem dúvida que um dos seus atributos que lhe permitiu a disseminação é ele não implicar o extermínio dos afazeres quotidianos. Ele concede a descoberta da realidade às tarefas mais comuns, permitindo a apreciação palpável do mundano. Essas tarefas são encaradas em si mesmas e não como meios para alcançar um qualquer fim. Porque o Zen começa no ponto em que nada há a ganhar, nenhum objectivo a ser alcançado; esse começo, que é afinal um retorno, acontece com a clara e distinta apreensão de que não nos é possível formar nenhuma identificação com qualquer conceito ou ideia da nossa natureza. No ponto em que tal impressão é sentida nos ossos, ocorre uma súbita transformação que permite transfigurar a habitual relação entre sujeito e objecto, conhecedor e conhecido; não é algo que seja interiorizado após uma longa lucubração em argumentos filosóficos. Tal certeza simplesmente acontece; torna-se uma relação real, uma unidade relacional em que o sujeito cria o objecto tanto como o objecto cria o sujeito. Não há independência entre o conhecedor e o conhecido, não há estranheza entre a experiência e aquele que a experimenta. Há portanto uma total disponibilidade ao que há porque sente-se que, embora decidamos tudo o que acontece, há uma naturalidade em todas as nossas acções. A passagem do tempo não é doravante dividida em passado ou futuro e sempre referenciada à vivência do momento presente, pois, de facto, só ele existe; não se trata de despir o homem das suas memórias ou imaginação, mas sim de desligá-lo da sua identificação com tal selecção fixa e contingente. É que à persecução do bom ou de qualquer outro ideal está também ligada a esperança ou a persecução do futuro; ora, a temporalidade no Zen não é vivida em função de nenhum horizonte; cada momento transmite a sua particular calma e auto-suficiência, não apontando para nenhum outro, estando contido em si mesmo. É então na aparente e desolada nudez austera, na ausência de apegos materiais e na recusa ao discurso simbólico que o Zen nos preten- 
de colocar, defendendo que essa abertura e sensibilidade ao desconhecido sem qualquer intenção e fim em vista é a nossa mais íntima e originária condição. E não fosse a sua extraordinária fecundidade nas artes e na vida japonesa ao longo dos séculos, desde a sua implementação, e toda esta filosofia mereceria talvez a conotação de niilista, como apelidou Nietzsche o Budismo ${ }^{3}$. De facto, ao valorizar-se a relatividade, o vazio, o difuso e recusar-se qualquer orientação ideológica, não se resvala no divórcio ontológico que parece atravessar alguma filosofia contemporânea. Nas culturas do Extremo Oriente, o vácuo é extremamente valorizado, pois, sendo fundo, contexto, é ele que possibilita o enquadramento da manifestação de toda a multiplicidade fenomenal. Estas considerações terão um enorme impacto nas implicações estéticas que seguem tais princípios. Se a forma de meditação, za-zen, é, sem dúvida, associada à prática do Zen por excelência, a exclusividade de aplicações não lhe pertence. Ao contrário das divisões entre artes e ofícios presente no Ocidente, nesta configuração qualquer mister é adequado, até certo ponto, para saborear o paladar do Zen. Assim, através da cerimónia do chá, da arte do arranjo das flores, da jardinagem, da pintura, das várias artes marciais, da poesia haiku, da cerâmica, muitos eram os caminhos, $d o$, que estimulavam a que o seu praticante se fizesse a si próprio através da sua prática ${ }^{4}$; esta deveria ser exercida não como um método de aperfeiçoamento ou consagração de produtos finais mas como uma forma de o discípulo ganhar familiaridade com os princípios consagrados no Zen ou no Taoísmo. A atitude deverá, novamente, ser orgânica, ou seja, é valorizada a aprendizagem e não a obtenção de resultados. Porque Te, virtude, é o incrível engenho e criatividade que não pode ser adquirido por um acumular de informações e a sua marca é conferir, quer às acções, quer às formas artísticas, a qualidade de um acontecimento fortuito. Dito isto, torna-se fácil compreender porque razão no Zen as obras de arte não apresentam de todo um tom representativo, mas são elas próprias a própria natureza. Porque se o homem não esteve nunca separado dela, não é lógico que o seu espírito possa criar algo que lhe seja exterior. Se a inteligência humana é apenas outro aspecto da ausência de finalidade e sem propósito da natureza, é inevitável que todas as suas criações sejam também elas tão espontâneas, quando embebidas da percepção Zen, quanto a maravilhosa evanescência absurda dos atributos naturais. Logo, se nesta tradição o espírito do homem nunca foi apartado da Natureza e apreendê-la é apenas estar com ela em comunhão sem realmente o pretender, torna-se verosímil acatar que as suas formas envolverão trâmites teóricos totalmente opostos aos da

${ }^{3}$ Friedrich Nietzsche, O Anticristo, Ecce Homo e Nietzsche contra Wagner, Lisboa, Relógio d'Água, 2000, §§ 20 e 23.

${ }^{4}$ Kakuzo Okakura, O livro do chá, Lisboa, Assírio e Alvim, 2007, p. 44. 
arte sacra no Ocidente e das restantes formas artísticas em geral. Porque se o Zen nos remete ao concreto e árido real e lhe retira as regularidades, semelhanças e diferenças, a natureza já não surge apenas como ordem mensurável e regular, mas irrompe-se no seu tal-qual(ismo) ${ }^{5}$. E assim compreende-se a ausência de adornos excessivos que preenchem por completo o objecto estético, tornando-se o vazio, condição da possibilidade, um elemento incontornável; assim se depreende que a figura humana ou tudo o que a recorde, presente já na própria figura do observador, esteja ausente; assim se aceita que a ausência do simétrico, do perfeito e do padronizável sejam omitidas em favor dos seus opostos, mais atreitos a serem completados pela imaginação. Ao contrário da concepção Aristotélica do Belo como o objecto completo e finalizado, em que as formas concorrem para o todo de uma maneira harmoniosa, o objecto estético do Zen favorece a sobriedade de motivos e adula à participação do seu contemplador na obra imperfeita. Um contraste evidente entre a concepção descrita e aquela que tem vindo a ganhar forma desde a modernidade é evidenciado no tema dos jardins. Sendo o jardim a categoria estética por excelência que se situa no fulcro da relação do homem com a arte e a natureza, essa visão está em franco contraste com a visão desenvolvida na Europa a partir da modernidade. O jardim francês coevo aos pensadores racionalistas exibe a mesma estrutura matemática e dedutiva que é colocada nas obras filosóficas dos seus autores e que conferiu um impulso enorme ao desenvolvimento científico. Ao rigor metodológico de um mecanicismo que exaura a realidade do seu elemento gratuito e inútil e lhe pretende perquirir as causas e os efeitos corresponde o jardim barroco; rico em linhas abstractas, em simetria, em formas geométricas e regularidades, ele encontra-se despojado dos acidentes caóticos que a natureza aparenta. O homem desvinculou-se ou achou-se fora da realidade e pretende agora explicá-la recorrendo à riqueza simbólica advinda do seu intelecto, mas dando-lhe a exclusividade de apreensão cognitiva. A adesão a este paradigma revestia-se como uma sede de conhecimento ou de marcha progressiva para a verdade ou para o progresso, ocultando porém uma vontade de conquista ou de poder insaciável. Ao desassossego que nos tem alimentado propõe pois o Zen a calma ou a ausência de pressa; porque não se vai a lado nenhum, há que reconhecer-se a beatitude apenas no mundano ${ }^{6}$; porque a estrutura do mundo é a estrutura do ser humano, toda a sua experiência é determinada tanto pelo seu equipamento cognitivo e pela estrutura dos seus sentidos, como pelos objectos externos cuja presença a mente revela. Ou numa linguagem mais poética, como o volume Zenrin Kushu indica:

5 Alan Watts, O Budismo Zen, pp. 78-80.

${ }^{6}$ Kakuzo Okakura, O livro do chá, p. 39. 
As árvores mostram a forma corpórea do vento; As ondas dão à luz a energia vital

De que maneira se pode concretizar um jardim que assente na perspectiva exposta?

Pretende-se abordar duas tipologias de jardim que beberam a sua inspiração nas doutrinas do Zen. Embora a sua influência na jardinagem acabe por ser total, há exemplos estilísticos em que a sua pureza apresenta-se menos contaminada por outras concepções. Aborda-se primeiramente o jardim de rochas, seixos e coios, típico dos mosteiros Zen. Ao contrário de muitas outras tradições búdicas, um mosteiro Zen pretende tão só ser um local de habitação para os monges. A sua capela não é lugar de adoração ou peregrinação, mas uma sala de estudo onde os estudantes se congregam para discutir e para a prática da meditação. Uma mudança funcional que ocorreu em muitos templos e residências foi a perda de utilidade do adro sul por ter-se adoptado uma entrada formal a norte, havendo portanto a possibilidade deste espaço adquirir novos contornos; uma primeira e necessária adaptação deu-se pela redução do tamanho do pátio, o que aponta já para uma necessária abstracção; ao efectuar-se uma redução de escala obedece-se também à precedência do todo sob as partes. Pela sua inserção num ambiente monástico, este jardim auxilia à meditação e à atenção ao imediato e, por isso, tende a ser mais abstracto que os restantes. É imediatamente reconhecido pela ausência total de água e pela presença minimal de vegetação, reduzida ao musgo ou a outras espécies frugais como os líquenes. A sua estrutura é um conglomerado maioritário de elementos da litosfera, tão cuidadosamente seleccionados e trabalhados que na sua presença somos transportados para a orla costeira, tal é a sua naturalidade; no entanto, torna-se óbvio estar-se perante uma criação artística que sem pretender emular a natureza, exige uma finura tão sensível e escrupulosa da parte do seu criador quanto a sua sintonia com ela; tal técnica pode ser descrita como um domínio perfeito da espontaneidade ou a arte de provocar acidentes sem propósito e sem tal se confundir como um produto do acaso. Ora, outro aspecto decorrente da filosofia implícita no Zen e cristalizada neste tipo de jardins é o carácter indefinido das fronteiras que o demarcam da arquitectura onde ele se insere; do jardim aos canteiros e daí ao alpendre e às alcovas e aos corredores do mosteiro não há nenhuma transição abrupta e súbita, prevalecendo sim o aspecto da continuidade e manifestando-se portanto a identidade dos vários constituintes do mesmo espaço. Tais fronteiras, ao mesmo tempo que demarcam, também supõem conexões, permitindo uma familiarização mais aguda com o carácter fluido e volúvel da nature-

7 Citado por Alan Watts, O Budismo Zen, p. 125. 
za e da vida humana, que nunca se detêm aos limites que lhes atribuímos. Esta implicação ontológica não se cessa ao mundo físico, já que pelos seus atributos, o próprio jardim impele e exige a ser experimentado e completado pela presença humana. Sem invocar o elemento da água, um jardim de rochas e seixos afirma-a por implicação; os sulcos existentes entre o mar de seixos são cultivados, com a ajuda de uma relha, em círculos ou eiras paralelas que recordam o comportamento associado aos lagos ou aos oceanos; os coios e a gravilha herdam, através da metáfora, o elemento aquático; o carácter rígido dos constituintes sáxeos evoca essa querida peculiaridade da água, a adaptabilidade a todas as circunstâncias, através dos padrões geométricos promovidos pelo ancinho; não só isso, também o som é invocado, ao constituir-se, através do empilhamento cuidadoso de vários seixos, um avatar, em forma lítica, da água. Todo este aspecto invocativo de um elemento pelo outro remonta para a necessária relatividade dos contrários e pela ausência de conflitos entre eles dada a sua dependência mútua. A assimetria é também promovida, nessa superficie de pedras onduladas cuidadosamente arranjada, pela colocação, aparentemente arbitrária, de rochas mais soberbas, cobertas de líquenes, musgos ou outras espécies rasteiras, invocando ilhas, navios ou penedos juntos ao litoral e tal é a harmonia dessas formações que as rochas parecem ter crescido nessa porção de terreno, depois de terem sido miraculosamente semeadas. Pela sua imperfeição, pelo zelo colocado na temperança, exibida pelo gosto no espaço vazio; pelo seu pudor em popular e ataviar excessivamente o jardim, realçando as suas possibilidades, abre-se então um diálogo infinito com o seu intérprete que acha-se no mesmo jogo dialéctico consigo próprio e que o jardim pressupõe, ou seja, promove-se a elucidação da noção de igualdade entre sujeito e objecto e da permanente mutabilidade das formas. Através da sua linguagem própria, o jardim lítico acaba por sugerir o que não ousa revelar.

A união entre o jardim e o espaço habitacional nele inserido revela mais importância no contexto da cerimónia do chá. Também importado da China, este ritual artístico é tão peculiar que assume conotações quase religiosas. É um culto do imperfeito, uma tentativa de apreender o belo no quotidiano e de sentir a grandeza nos pormenores ${ }^{8}$. Tudo nela estava sujeito ao arbítrio do mestre do chá, ou seja, a sua influência espalhou-se à jardinagem, à arquitectura, à cerâmica, ao arranjo das flores, à cinzelagem. Nela promovia-se a arte do ajuste consigo próprio e com a vida, o que é em si mesmo uma filosofia enformando uma estética. Novamente, o conceito de vácuo da ontologia búdica promove, na estética, o poder da alusão e nesse processo de completar o imperfeito, o intérprete acha-se pertencendo à própria obra de arte. A presença do jardim nesta cerimónia

${ }^{8}$ Kakuzo Okakura, O livro do chá, p. 87. 
pretende preparar e envolver o participante na atmosfera que a sala de chá pretende concretizar; o roiji - caminho entre o pórtico de entrada e a divisão da cerimónia - é um estágio primeiro na meditação. Encaminhando-o para uma apreciação estética da banalidade, esta vereda era percorrida por todo o tipo de membros da sociedade hierárquica do Japão, com o intuito de lhes quebrar os laços que os amarravam ao mundo exterior; percorrendo-a e mergulhado no jardim, o participante deveria sentir-se despido dos vínculos convencionais da sociedade e dos arrufos civilizacionais, reduzindo-se à sua fragilidade vibrátil e contempladora, o que lhe permitiria a fruição completa da preciosidade dos gestos, das atitudes e do ambiente da sala de chá. Pela sua naturalidade e harmonia, o jardim imbuía o transeunte na multiplicidade das suas formas, na riqueza dos seus sons e retirava-o ao torvelinho urbano e aos deveres de classe, ressuscitando-lhe a atenção para a dádiva de cada pormenor natural e preparando-o para a consideração de cada acontecimento enquanto único, irrepetível e contendo toda a eternidade. A arte do jardim era tão elevada que alguns mestres de chá arrogavam a capacidade de induzir determinada emoção de acordo com alguma configuração dos elementos naturais e das ocasiões suscitadas pela temporalidade das estações; uma entrada feita ao lusco-fusco outonal e sujeita à camada branda e cálida que essa atmosfera imprimia nas composições do jardim provocaria decerto uma impressão diferente duma cerimónia marcada para o começo da noite, em que a luz silenciosa da lua conferia uma aura de mistério, melancolia e singularidade ao roiji. Ou seja, há um paralelismo entre a natureza e o homem, desta feita numa acepção emocional; ambos se provocam e afectam dos seus respectivos ecos; esta característica ocorria já nos poemas haiku, onde, evocando um profundo sentimento de solidão, um poeta Zen permitia-se resumir o seu estado de espírito asserindo:

Calou-se o sino
o que chega a mim agora é o eco
das flores
Uma rã mergulha
no velho tanque...
O som da água ${ }^{9}$

Os mestres do chá, preferindo dirigir a atenção para algum motivo central, evitavam a reiteração inútil de motivos estéticos; no jardim, esta direccionalidade impelia ao uso módico da cor e do emprego de matizes

${ }_{9}$ Matsuo Bashô, O gosto solitário do orvalho seguido de $O$ caminho estreito, Lisboa, Assírio e Alvim, 2003, p. 24 e p. 26. 
cromáticos que raro, senão nunca, existem na natureza. $\mathrm{O}$ jardim, na sua naturalidade, possui necessariamente um contexto específico que remete para o todo, tornando-se portanto os adereços uma asserção do supérfluo. A simplicidade de tons e espécies vegetais evitava tornar o jardim numa concentração abusiva de toda a flora japonesa, conferindo-se a apreciação aos seus detalhes e ao seu jogo com a temporalidade e à sinergia relacional dos seus elementos os verdadeiros factores de apreciação. $\mathrm{O}$ jardim não era, enquanto obra humana e obra natural, uma substância estática; era projectado como abrangente e complementar a todas as quatro estações, não fazendo sentido o privilégio duma estação específica; ele estava necessariamente inacabado e sujeito à temporalidade e aos apetites sazonais, devendo o seu colaborador trabalhá-lo como se lhe pertencesse, estando o seu vigor nas suas possibilidades de crescimento e de retorno sob diferentes formas. Na sala de chá, sujeitos a tão subtil evento, os convidados eram livres para observar, comentar ou partilhar o silêncio borbulhante de impressões que advinham do jardim. A Primavera e o Outono assumiam-se, nesse campo, como épocas especialmente abundantes no significado atribuído aos fenómenos naturais; nesse contexto, a árvore por excelência que melhor dimana, em si, o conceito de transitório é a flor de cerejeira; pela sua flor possuir um período de vida curto, a sua ascensão e queda é de valor muito particular para os japoneses. Partilhar a visão dalguns dos seus braços brotando viço e desabrochando-se em minúsculos e receosos botões até se comporem em algo de novo e inocente era algo apreciado apenas quando em contraste com a dança rósea das pétalas chovendo até ao chão e deixando glabra os outrora abundante braços da árvore; essa tempestade onírica evoca a anulação do que antes se sabia belo e encerrava vida, realçando-se por isso o carácter comum que o passageiro tem com a vida humana e os seus desejos, o que, ao invés de resvalar num sentimento de terror, culmina numa aceitação e valorização do presente como acontecimento único, apesar das suas vicissitudes, o que é uma marca indistinguível do Zen.

Pela sua valorosa sistematização e convergência com as perspectivas apresentadas, julga-se que ambas perspectivas ganharão relevo se confrontadas e esclarecidas quanto aos seus possíveis pontos em comum; reporta-se à proposta kantiana exposta na Crítica da Faculdade do Juízo acerca do conceito da natureza ser alargado pela introdução de uma nova faculdade; nesta perspectiva, pretende-se julgar a adequação do jardim de influência Zen aos conceitos desenvolvidos pelo filósofo alemão. Esta obra constitui o último elemento duma tríplice sistemática de categorização do equipamento intelectual humano e tem como objectivo conferir uma maior liberdade de avaliação dos objectos que, apesar disso, não invalide a teorética avançada anteriormente; trata-se de invocar uma possível harmonização entre a liberdade humana e o paradigma mecanicista 
conferido, na sua época, à natureza. Ora, para tal, Kant introduz uma regra geral pela qual os juízos sobre a natureza não se resumam apenas a uma subsunção automática dos produtos particulares da natureza nos conceitos arquitectados pelas categorias do entendimento. Ou seja, há um aumento da capacidade inteligível do sujeito transcendenta ${ }^{10}$, promovido através da mediação da faculdade do juízo com as restantes faculdades constituintes do ânimo. A faculdade do juízo ganha um comportamento reflexivo, suprimindo-se o anterior comportamento, apenas determinante. É nesse jogo reflexivo entre as várias formas múltiplas da natureza que a nova forma de ajuizar acha-se na necessidade de encontrar uma lei para si mesma. Essa lei é a conformidade a fins da natureza, nas suas componentes estética e teleológica, traduzida no sentimento de prazer e desprazer. Embora se reconheça plenamente que a natureza não padece de qualquer intenção final, ela só poderá ser ajuizada, na sua espontaneidade, como se procedesse segundo fins ${ }^{11}$; ora, as suas belas formas exercem um irresistível desejo para a reflexão, o que obriga a que o sujeito alargue a sua tópica categorial, enriquecendo as suas perspectivas. A perspectiva programática adiantada na Crítica da Razão Pura que exigia que cada objecto, na sua determinação, fosse enquadrado, subsumido, no sistema categorial, acaba por retirar a cada particular a sua particularidade; com a mobilidade diferente dada à faculdade da imaginação, é possível uma elasticidade entre a razão e o entendimento e cada particular, ficando assim a experiência estética atribuída ao ajuste entre os aspectos cognitivos e a possibilidade de cada particular alternar-se em matizes de representações. Ora, na experiência estética do sublime dá-se a situação caricata da imaginação se deparar com a impossibilidade de alcançar os limites da sensibilidade e do entendimento; à harmonia das formas e entre estas, a do sujeito, opõe-se o desprazer, o assustador, o inconcebível, arvorados pelo desmoronar da inteligência e do conceptual.; a sua associação com a temporalidade é também transfigurada, tornando-se própria dessa nova configuração da interferência entre as capacidades intelectuais e a natureza: introduz-se a dimensão do acontecimento e do agora, preterindo-se o consequente, o sucessivo, o decorrente, arrostando-se o fenomenal ao sujeito como que desligado do tempo: o estético acaba por singularizar-se pela sua ausência de fins, de propósitos e que na referência ao agora se atribui o seu próprio telos.

10 Immanuel Kant, Crítica da Faculdade do Juízo, Lisboa, IN-CM, 1998, Introdução V: "O princípio da conformidade a fins formal da natureza é um princípio transcendental da faculdade do juízo".

11 Leonel Ribeiro dos Santos, "Kant e a ideia de uma poética da Natureza", Philosophica, 29 (2007), 19-34. 
É na teorização do sublime, em especial a perda e o ganho simultâneo que ele representa, que se poderá estabelecer um primeiro contacto com a perspectiva do Zen. De facto, embora essa experiência seja, em Kant, apenas passível de ser vivida em confronto com algum objecto natural, é-lhe exigido, como condição, um sentimento de desconforto e desprazer. Ora, apesar de o Japão ser um país acossado invariavelmente por terramotos, tufões e actividade vulcânica, a sua arte não apresenta referência aos aspectos terríficos que tal vivência despoleta e à inerente pequenez face ao universo em que o homem se observa, reconhecendo essa oscilação entre alguns aspectos do mundo natural e a sua insondável insuficiência cognitiva para os esclarecer, abarcar, nomear. Sem pretender fornecer uma explicação cultural ou psicológica do povo japonês, é possível, no entanto, afirmar que os fundamentos metafísicos em que tal arte se arrimava, por potenciarem a união com a natureza e escaparem-se à possibilidade do conhecimento conceptual duma realidade última e da natureza do sujeito, favorecem a tradução dos aspectos mais ininteligíveis da natureza em termos da sua emulação natural. Por outras palavras, se o homem do Zen sabe-se como parte integrante dum todo a qual todas as categorias são desadequadas, qualquer experiência que lhe mostre os limites da sua gnosiologia, como parece ser a do sublime, não poderá constituir uma excepção à sua vivência, pois como ficou deveras explicado, o Zen promove o retorno a um estado do tal-qual(ismo) em que toda e qualquer categorização e classificação do real em termos das suas diferenças, semelhanças e regularidades é preterida a favor de um acesso directo e súbito; concluindo, se as artes do Zen não espelham o sublime, tal deve-se ao seu conceito de natureza não estar baseado numa arquitectura de conceitos que a experiência do sublime abala. Movendo-se na espontaneidade própria da natureza, o Zen acaba por atribuir ao sujeito aquela técnica da Natureza ${ }^{12}$ que Kant classifica como a espontaneidade de produção, da natureza, que se empresta à arte, enquanto que a arte concede à natureza a intencionalidade, sem a qual a faculdade de juízo, na sua conformidade a fins, não poderia desenhar a experiência estética. Kant concede inclusive a prioridade à natureza na sua relação com a arte, ao ponto de lhe atribuir, na sua teleoformidade, a capacidade de alargar o nosso conceito de natureza para lá do equipamento mais rígido das anteriores Críticas; quanto à possibilidade da adequação da sua teoria estética da natureza aos exemplos do jardim japoneses apresentados, ela parece ser bastante favorável, uma vez que em todos eles é claro o cuidado exímio, baseado no cultivo da naturalidade do criador, em potenciar um jardim tão natural que ele esconde por completo o artificio humano.

12 Leonel Ribeiro dos Santos, "Kant e a ideia de uma poética da Natureza", 19-34. 
Para concluir e usando mais um conceito kantiano, podemos dizer que o Zen, pela sua influência não só nas artes e ofícios, mas também na conduta humana, pretende transferir o génio, favorecido da natureza, mediante o qual a natureza dá a regra à arte ${ }^{13}$, a todos os campos da existência humana. Se o génio é aquela capacidade que não admite qualquer destrinçar do seu funcionamento e que ao mover-se, na sua técnica, como se não procedesse a fins, imprime tamanha espontaneidade aos seus artifícios que eles só se julgam como pertencentes à natureza, o Zen pretende radicar e desenvolver essa capacidade como o maior atributo humano; a sua expressão não é exclusiva às artes, já que no seu culto do tal-qual(ismo), ele pretende estimular a noção que o mundano e o banal são também fontes de beatitude.

\section{Bibliografia}

Eugen Herrigel, Zen e a arte do tiro com arco, Lisboa, Assírio e Alvim, 2007. Gunter Nitschke, Japanese Gardens, Taschen, 1999.

Lorella Montanelli, Il giardino Zen e l'architettura dello spirito, Istituto Universitario di Venezia, 2003.

Taisen Deshimaru, Verdadeiro Zen, Lisboa, Assírio e Alvim, 2005.

\section{ABSTRACT \\ THE JAPANESE GARDEN IN CONTEMPORARY NATURE AESTHETICS}

This paper aims to depict the main philosophical lines that, deriving from Japanese Zen Buddhist precepts, guided and allowed the development of the Japanese garden. Some necessary historical, geographical and cultural references will have to be drawn if an acute portrait of its specificity is to be made; nonetheless, as it should be clear along the article, its guiding lines are universal, as the spread and influence of the Japanese gardens in other cultural contexts illustrates it. And that could only be due to the aesthetic and ontological autonomy, relevance and fertility that fosters this style of gardening. The vision that crosses the Japanese garden will also be exposed through the resemblances and differences with other authors, namely Kant and the concepts sustained by his Critique of Judgment, which therefore mutually enriches the clash of both perspectives.

13 Immanuel Kant, Crítica da Faculdade do Juízo, $\$ 46$ a 49. 


\section{RESUMO}

\section{O JARDIM JAPONÊS NA ESTÉTICA DA NATUREZA CONTEMPORÂNEA}

Neste trabalho pretende-se explicitar as principais ideias, decorrentes do Budismo Zen, que presidiram e possibilitaram o advento e fecundo desenvolvimento do jardim japonês. Algumas referências históricas, geográficas e culturais deverão ser feitas quando se pretende abordar toda a sua especificidade de um modo fidedigno; contudo, como se procurará demonstrar, as suas linhas orientadoras são tão universais quanto a disseminação global dos vários estilos de jardim japonês noutros contextos culturais que não o país do sol nascente o testemunha. E tal só poderá radicar na própria autonomia, pertinência e fertilidade da estética e ontologia das quais eles estão imbuídos. Essa visão que atravessa o jardim japonês será também ilustrada, quando necessário, através das várias semelhanças e diferenças no confronto com outros autores, nomeadamente Kant e os conceitos sustentados pela sua Crítica da Faculdade do Juízo, o que permitirá um enriquecimento mútuo de ambas as perspectivas. 